\title{
CORNEAL ENDOTHELIAL CHANGES IN CYTOMEGALOVIRUS RETINITIS
}

\author{
S. M. MITCHELL ${ }^{1.2}$, K. BARTON ${ }^{1}$ and S. LIGHTMAN ${ }^{1}$ \\ London
}

\begin{abstract}
SUMMARY
Reticular deposits on the corneal endothelium together with fundus changes typical of cytomegalovirus (CMV) retinitis have been noted in patients with acquired immune deficiency syndrome (AIDS). The aim of this study was to characterise this finding using specular microscopy and to assess the potential of this clinical sign as a screening tool which could be performed rapidly at the slit lamp without the need for dilatation of the pupil. Sixty male homosexual patients with a diagnosis of AIDS as defined by the Center for Disease Control (Atlanta, 1987) were examined at their first visit to the ophthalmic clinic. The cornea was examined at the slit lamp prior to fundal examination and the presence or absence of the characteristic endothelial changes noted. CMV retinitis was diagnosed on the basis of the fundal appearance together with confirmation of the diagnosis by analysis of a vitreous sample. As a diagnostic sign of CMV retinitis the endothelial changes had a positive predictive value of 94.7\% and a negative predictive value of $75.6 \%$. Although the presence of the endothelial changes always indicates the presence of CMV retinitis it is not a sign which is found in a high enough proportion of patients to allow its reliable use as a screening tool.
\end{abstract}

Cytomegalovirus (CMV) retinitis is the most common ocular problem in patients with the acquired immune deficiency syndrome (AIDS), occurring in $25-40 \%$ of this group. ${ }^{1.2}$ If untreated it leads to irreversible blindness. At present, a diagnosis of CMV retinitis is made on the basis of the clinical appearance of the retina on fundoscopy. ${ }^{3-5}$ In view of the serious consequences of missing a diagnosis of CMV retinitis the ophthalmologist is frequently asked by both AIDS physicians and patients to perform a fundal examination for the purpose of reassurance. A full fundal examination in these circumstances is costly in terms of time to both the patient and the ophthalmologist.

From: 'Department of Clinical Science, Institute of Ophthalmology, Moorfields Eye Hospital, London, UK: 'Department of Virology, University College London Medical School, London, UK.

Correspondence to: Miss Suzanne Mitchell. Professorial Unit, Moorfields Eye Hospital, City Road, London EC1V 2PD, UK.
Corneal precipitates and aqueous flare have been observed in patients with AIDS ${ }^{6.7}$ and Severin et al.$^{8.9}$ have reported several cases in which characteristic corneal endothelial signs were associated with CMV retinitis. This study describes these endothelial changes and assesses whether this clinical sign can be regarded as pathognomonic for CMV infection and therefore be used to screen for the presence of retinitis.

\section{PATIENTS AND METHODS}

Sixty male homosexual patients with CD4 counts lower than 200 cells $/ \mathrm{mm}^{3}$ were included in this study after giving their informed consent. All the patients also had a diagnosis of AIDS as defined by the Center for Disease Control (Atlanta, 1987). Slit lamp photography and specular microscopy (Keeler-Konan specular microscope) were performed on 2 patients.

All patients were examined at their first visit to the ophthalmic clinic. The cornea was examined by one ophthalmologist at the slit lamp prior to dilatation of the pupil and the presence or absence of the characteristic endothelial signs noted. Fundal examination by indirect ophthalmoscopy was performed by a second ophthalmologist who was unaware of the result of the corneal examination. All patients with a clinical diagnosis of CMV retinitis underwent vitreous biopsy and the vitreous sample was tested for the presence of CMV DNA using previously published methods. ${ }^{10}$

The sensitivity, specificity and predictive value of the corneal changes as compared with indirect ophthalmoscopy in diagnosing CMV retinitis were calculated using Bayes' theorem.

\section{RESULTS}

Slit lamp examination revealed a normal corneal epithelium and intact stroma. Endothelial precipitates were distributed diffusely over the entire corneal endothelium but unlike those seen in Fuchs' heterochromic cyclitis were mostly non-pigmented. The deposits were arranged 


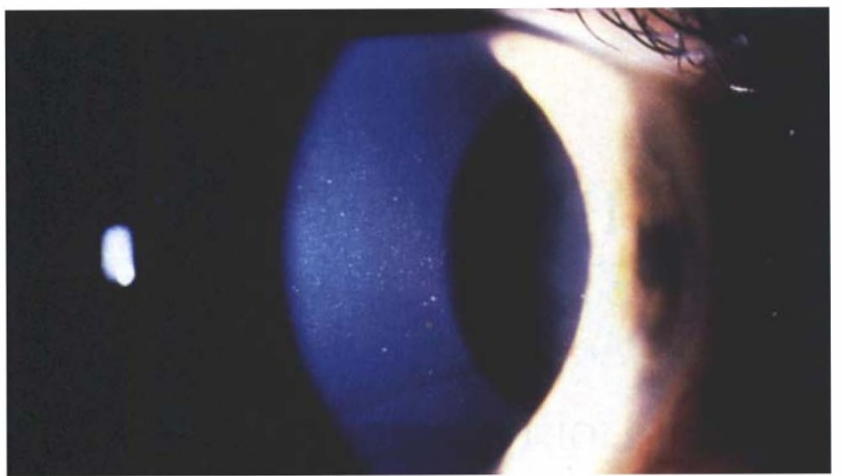

Fig. 1. Slit lamp photograph showing retroendothelial precipitates reticularly arranged and diffusely distributed.

in a reticular fashion (Fig. 1). Occasional cells were seen in the anterior chamber. Wide-field specular microscopy showed small endothelial cells of normal density and regular pattern. Mild polymegethism was apparent. Scattered light highlights and focal dark events were seen throughout the field (Fig. 2).

Twenty-eight patients had CMV retinitis diagnosed by examination of the fundus with the indirect ophthalmoscope. In all cases CMV DNA was detected in the vitreous sample as well, confirming the diagnosis. Eighteen of these patients had the characteristic corneal changes. Thirty-two patients had no evidence of CMV retinitis on fundal examination, and of these 31 had no evidence of the characteristic fundal changes.

The sensitivity of the corneal sign in diagnosing CMV retinitis was therefore $64.3 \%$ and the specificity was 96.9\%. As a diagnostic sign of CMV retinitis the endothelial changes had a positive predictive value of $94.7 \%$ and a negative predictive value of $75.6 \%(K=0.6)$.

\section{DISCUSSION}

The characteristic slit lamp and specular microscopy findings can be interpreted in the following way. The focal dark events probably represent leucocytes lying under the corneal endothelium, although cellular and local oedema can produce a similar picture. The light highlights could be explained by scattered pigmentation, but experimental work comparing microscopic appearances with histological and scanning electron microscopic studies have shown that this picture can also be produced by spindle-shaped macrophages. ${ }^{11}$ The endothelial findings seen in this study would be consistent with a mild endotheliitis with lymphocyte and macrophage involvement. Further histopathological studies are required to resolve the question as to whether CMV actually infects the endothelial cells to produce these changes.

The results of this study suggest that the endothelial changes seen in patients with AIDS are pathognomonic for CMV retinitis. All the patients in this study were assessed at the time of their first visit to the ophthalmic clinic and thus in $64.3 \%$ of patients the corneal signs were present at the time of a new diagnosis of CMV retinitis. In $96.9 \%$ of the patients without CMV retinitis there were no corneal changes. Despite the fact that the characteristic

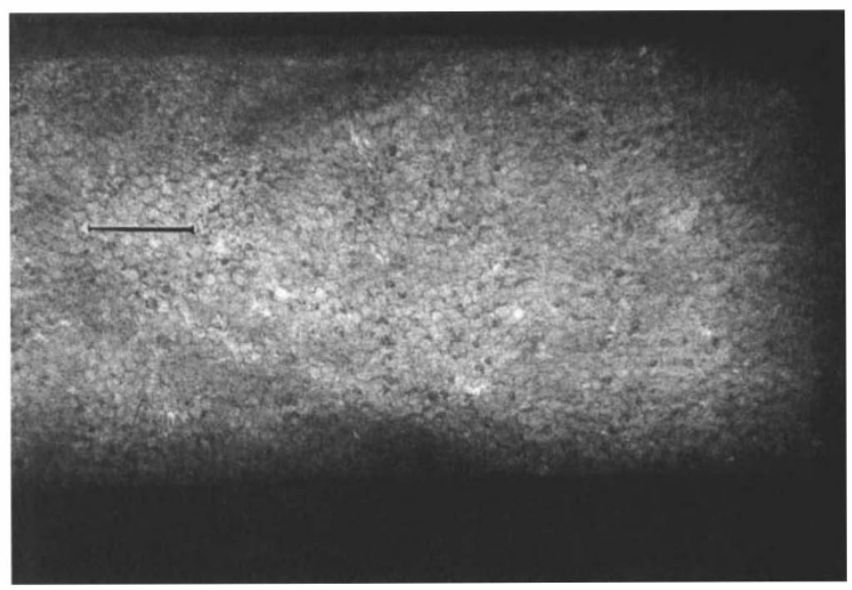

Fig. 2. Specular micrograph of corneal endothelium showing scattered dark events and light highlights. Scale bar represents $100 \mu \mathrm{m}$.

endothelial changes were highly specific for CMV retinitis this lack of sensitivity makes them unreliable as a screening tool. It was interesting to note that the corneal changes did not resolve once the patient was commenced on appropriate therapy and the retinitis had become clinically quiescent.

More recently several groups have attempted to use laser flare photometry as a means of evaluating intraocular inflammation in patients with AIDS. Aqueous flare evaluations have been of some value in diagnosing the presence of ocular inflammation but have not yet been able to discriminate between the variety of infections that involve the eye in these patients. Results presented thus far have not bettered the simple examination of the cornea at the slit lamp as advocated in this study. ${ }^{12}$

It must therefore be concluded that at present the only way to exclude a diagnosis of CMV retinitis is by full ophthalmic examination including fundoscopy with the indirect ophthalmoscope and pupillary dilatation.

S. M. Mitchell is funded by a Wellcome Trust Vision Research Fellowship. We thank Mr S. Tuft and Miss H. Laganowski for their help with the specular microscopy.

Key words: AIDS, Corneal endothelium, Cytomegalovirus, Retinitis.

\section{REFERENCES}

1. Friedman AH, Orellana J, Freeman WR, et al. Cytomegalovirus retinitis: a manifestation of the acquired immune deficiency syndrome (AIDS). Br J Ophthalmol 1983;67: 372-80.

2. Freeman WR, Lerner CW, Mines JA, et al. A prospective study of the ophthalmic findings in the acquired immune deficiency syndrome. Am J Ophthalmol 1984;97:133-42.

3. Jabs DA, Enger C, Bartlett JG. Cytomegalovirus retinitis and the acquired immunodeficiency syndrome. Arch Ophthalmol 1989;107:75-80.

4. Holland GN, Buhles WC, Mastre B, Kaplan HJ. A controlled retrospective study of ganciclovir treatment for cytomegalovirus retinopathy. Arch Ophthalmol 1989;107: 1759-66.

5. Bloom JN, Palestine AG. The diagnosis of cytomegalovirus retinitis. Ann Intern Med 1988;109:963-8.

6. Newman NM, Mandel MR, Gullett J, Fukjikawa L. Part of a 
new syndrome of acquired immunodeficiency. Arch Ophthalmol 1983;101:396-401.

7. Contrill HL, Novak A, Cameron D, Skelnik DL. Corneal endothelial changes in CMV retinitis. Ophthalmology 1987; 94:124.

8. Severein M, Hartmann C. Endothelial alterations in AIDS with cytomegalovirus infection. Ophthalmologica (Basel) 1988;196:7-10.

9. Severin M, Hartmann C, Schadlich HJ, Brunner R, Rasokat H. Endothelprazipitate und Zytomegalieinfektion. Fortschr Ophthalmol 1989;86:227-31.
10. Mitchell SM, Fox JD, Tedder RS, Gazzard B, Lightman S. Vitreous fluid sampling and viral genome detection for the diagnosis of viral retinitis in patients with AIDS. J Med Virol (in press).

11. Hartmann C. Morphologische und morphometrische Untersuchungen des Hornhautendothels: eine klinische und experimentelle Studie. Cologne: Habschr, 1986:1-240.

12. Muccioli C, Belfort Jr R, Podgor M, et al. The diagnosis of intraocular inflammation and CMV retinitis in HIV infected patients by laser flare photometry. Invest Ophthalmol Vis Sci (ARVO Suppl) 1993;34:2008. 